contamination of the equipment at three or six months-five of the compressor tubing (four with obvious condensation), 17 of the nebuliser reservoirs (eight of which had residual fluid), and 13 of the (17) syringes. Most patients washed their nebulisers and attempted to dry them, but three patients dried their equipment by blowing air through the nebuliser via their compressor and none of these had contamination. The bacterial isolates were all environmental organisms of low pathogenicity-mainly oxidase positive and oxidase negative Gram negative rods, diphtheroids, and Staphylococcus epidermidis. Although these represent a potential source of infection, none of our patients developed infection with these organisms during the six months.

We therefore now recommend that, as well as regular washing of nebulisers, an essential part of cleaning is to dry the equipment thoroughly by blowing air through the tubing and nebuliser with the air compressor. As individual nebules are now commonly available the use of syringes to draw up nebuliser solution is rapidly declining and we no longer recommend their use.

C M B HIGgs

PATRICIA JONES

A R TANSER

Chest Unit,

Royal United Hospital,

Bath BA1 3NG

SIR,-We agree with Ms Kate L Barnes and colleagues ( 3 October, p 812) that bacterial contamination of home nebulisers may be a potential source of pathogens. Home nebulisers should be washed after use, then dried, and stored dry. The nebuliser should not be stored in a dilute solution of disinfectant, as recommended, since this could prove to be a further source of contamination.

MaEve G L Keaney L A GANGUL

Hope Hospital,

Salford M6 8HD

\section{The blood transfusion service and the National Health Service}

SIR,-Dr J R Y Ross (3 October, p 850) suggests that the Scottish Blood Transfusion Service may cope better because it receives more than twice as much money per head of population as its counterpart in England. As director of one of the Scottish transfusion centres I suggest that this figure needs further examination as there are several reasons why the two sets of expenditure figures quoted are not directly comparable.

Firstly, the figures for Scotland include the full cost of the Protein Fractionation Centre, which produces virtually all the plasma fractions used in Scotland (and Northern Ireland). I suspect that the English figures do not include the full costs of the Blood Products Laboratory at Elstree. This difference would be appreciable since the Protein Fractionation Centre represents around $20 \%$ of the expenditure of the Scottish transfusion service.

Secondly, there are several important differences in the activities of the Scottish and English services. For example, for about half the Scottish population the regional transfusion centres provide not only blood collection and processing but also the full range of routine and emergency hospital blood banking services. At my own centre, for example, we do all the hospital blood banking for the whole of Edinburgh except one hospital; this includes compatibility testing of nearly 30000 patient samples per year and accounts for an appreciable proportion of our total expenditure. Other services provided by Scottish regional transfusion centres include tissue typing, the regional cell separator unit, and immunology services. The Scottish centres also produce reagents for blood typing, which have an estimated commercial value of ove £lm a year.

Finally, the simple arithmetic of blood collection may account for a fair part of the cost differential. The blood collection rate in Scotland in 1985 was about 58000 units per million population per year compared with an average in England of about 45000 . Whether or not one accepts that the official handling charge of $£ 23$ per unit bears any relation to the actual cost of collecting and processing a uni of blood, a higher collection rate will inevitably lead to a higher per caput cost for the service concerned.

We have now entered a period when most of Britain's transfusion centres are under great pressure to maintain adequate levels of blood collection. The many new problems we face will almost inevitably lead to increases in the cost of providing an adequate transfusion service. My plea is that we do not cause extra difficulties for our national effort to provide a safe and cost effective transfusion service by using incomplete financial information

\section{B L McClelland}

Royal Infirmary,

Edinburgh EH3 9HB

\section{Potassium citrate: soothing but not harmless?}

SIR,-I learnt the Lesson of the Week (17 October, p 993) the hard and stupid way-in other words, by personal experience.

A few days after unexceptionable transurethral prostatic resection painful micturition. convinced me that I had an infection. While awaiting the culture result I persuaded my sympathetic house surgeon to prescribe potassium citrate mixture on the grounds that it could do no harm, and, anyway, when I had been a houseman in the same hospital 44 years previously it was about the only relevan medication available. The mixture arrived at the bedside, and I proceeded surreptitiously to consume it, unmonitored, in at least double the prescribed dosage. After 48 hours to the urinary discomfort were added the most appalling nausea, peculiar muscle weakness, and spontaneous vomiting, all of which terrified me and mystified my carers until electrolyte measurement revealed hyperkalaemia $(6.7 \mathrm{mmol} / \mathrm{l})$ and taught them to beware of doctors as patients. The culture, incidentally, was sterile. My general and renal health has been excellent, before and since.

South Mimms,

A L FAWDRY Hertfordshire EN6 3PS

\section{Soviet health care at first hand}

SIR,-I recently had first hand experience of being admitted to hospital in Samarkand, Russian Central Asia. As suggested by Michael Ryan in his article on funding for the Soviet health service (12 September, p 652), the resources of the hospital were minimal and the facilities and equipment very basic indeed.

While touring the region with my husband I was taken ill during the night with frequent and violen bouts of sickness and diarrhoea beyond the normal expected hazard of foreign travel. As this particular attack was so severe my husband called on the hotel staff for help, our own preventive medication brought with us from the UK proving ineffectual.
This account is not intended as a criticism of the $\underline{\underline{T}}$ treatment I received. It was prompt, thorough, 3 and effective and I suffered no recurrence. The $\mathbb{\otimes}$ hotel staff quickly summoned their paramedical $c$ team of three, who through an interpreter inquired of my symptoms and then advised my dispatch to the nearest hospital for treatment. At this point I learnt that another of our party had suffered similar symptoms and was at that moment on his way to hospital. As soon as the ambulance returned I was given a towel in case I was sick on the journey (which I was) and driven the short distance to the nearest hospital.

The entrance to the hospital was kept permanently barred by iron doors and immediately closed behind the ambulance. When visiting later my husband told me that he was admitted only after scrutiny through an iron grille as if he were visiting a prisoner. He also glanced through the windows of the various single storey buildings which made up the compound and noticed beds in the various wards that were so close there was no room to walk between. The "ward" I was admitted to proved to be an $\mathrm{L}$ shaped room about $5 \mathrm{~m}$ by $4 \mathrm{~m}$ containing five bedsteads with springs like hammocks. In one of these beds was the other man of from my hotel, whom I came to know rather well since his bed was next to mine with two chairs draped with a blanket as a screen. We shared a toilet which adjoined the room and which indeed $\vec{N}$ had to be passed through to enter. This toilet had a permanently running defective cistern which ف่ would not flush and no seat. However, there was a $O$ bath, from the tap of which a basin could be filled and poured into the toilet pan. The bath itself had $\vec{A}$ obviously not been used for a long time because the $Z$ waste pipe was not connected. As a final indignity this toilet had no door and was open to the street outside. The room itself had two large windows, one of which had an ill fitting fly screen. Neither had blinds or curtaining and passers by could (and did) peer in at what was taking place within. There were three light switches, but only a single fluorescent tube worked, and there were no power points at all. The bedding was of doubtful cleanliness, cracked linoleum was on the floor, decoration was long overdue, and many flies were a constant irritation.

Both of us patients received similar treatment in quick succession. The absence of anyone who could speak English (or French or German tried in turn) made communication difficult, but after we had made our symptoms known by signs the doctor and three nurses swung into action. I must again emphasise that I do not complain at the treatment received, which was effective, if crude. I was given a pail of water and an enamel saucepan and by signs instructed to drink as much as I could as quickly as I could to induce vomiting. When this was only partially successful I was advised to put two fingers down my throat to complete the 을 process. Then I was given an enema with warm $N$ water to complete the process of clearing out and a $\sigma$ blood sample was taken. Finally I was given three $\frac{D}{O}$ jam jars (without lids) and asked to provide appropriate specimens for analysis. This I did with $N$ some difficulty in the toilet with no door. I was N then connected to a glucose and water drip through a needle in my arm (seven attempts to find a vein and no disposable needles). Altogether I received two pints.

I was kept in the hospital for about 24 hours, during which time $I$ had one wash in a none $T$ too clean basin (through the intervention of my husband with the aid of an acquired phrase book). Some biscuits, salty water, and yoghourt were $\bar{D}$ provided as sustenance. Neither of us could face the two hard boiled eggs that were also supplied. Both my fellow patient and I had a restful night and 8 as far as we know were not disturbed by any visit 